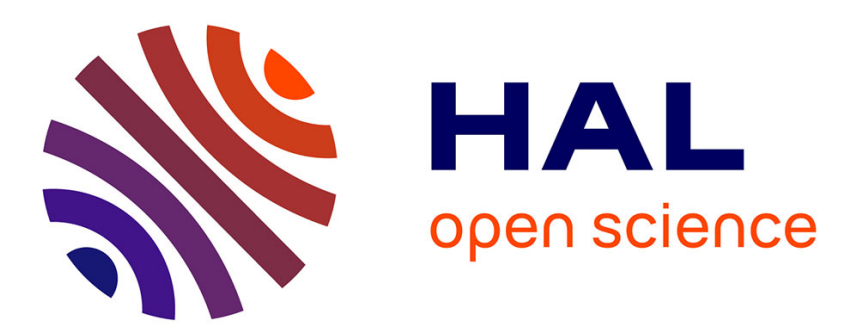

\title{
Complexity Management in Product/Process Simultaneous Design for Implementing a Fresnel Thermodynamic Solar Plant
}

Roozbeh Babaeizadeh Malmiry, Nicolas Perry

\section{- To cite this version:}

Roozbeh Babaeizadeh Malmiry, Nicolas Perry. Complexity Management in Product/Process Simultaneous Design for Implementing a Fresnel Thermodynamic Solar Plant. Lecture Notes in Production Engineering - Smart Product Engineering, Springer, pp.411-420, 2013, 10.1007/978-3-642-308178_40. hal-00941040

\author{
HAL Id: hal-00941040 \\ https://hal.science/hal-00941040
}

Submitted on 3 Feb 2014

HAL is a multi-disciplinary open access archive for the deposit and dissemination of scientific research documents, whether they are published or not. The documents may come from teaching and research institutions in France or abroad, or from public or private research centers.
L'archive ouverte pluridisciplinaire HAL, est destinée au dépôt et à la diffusion de documents scientifiques de niveau recherche, publiés ou non, émanant des établissements d'enseignement et de recherche français ou étrangers, des laboratoires publics ou privés. 


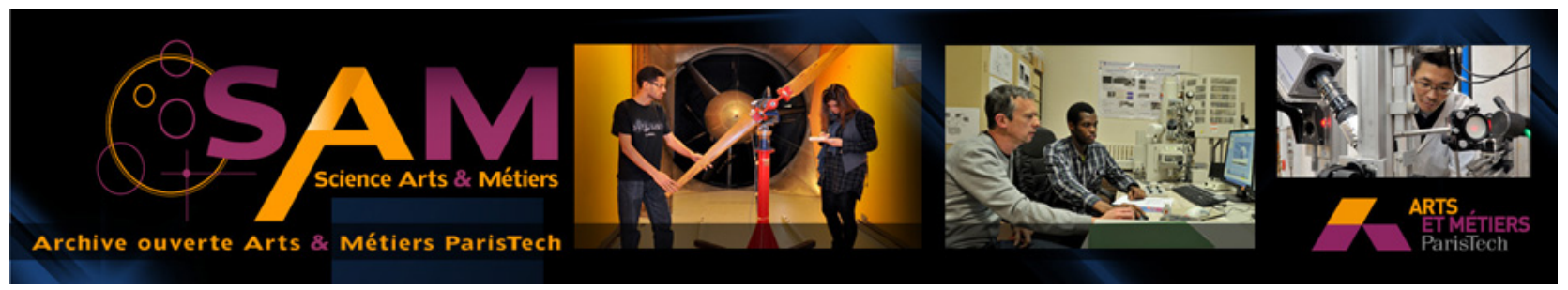

Science Arts \& Métiers (SAM)

is an open access repository that collects the work of Arts et Métiers ParisTech researchers and makes it freely available over the web where possible.

This is an author-deposited version published in: http://sam.ensam.eu Handle ID: .http://hdl.handle.net/10985/7737

\section{To cite this version :}

Roozbeh Babaeizadeh MALMIRY, Nicolas PERRY - Complexity Management in Product/Process Simultaneous Design for Implementing a Fresnel Thermodynamic Solar Plant - 2013 


\title{
Complexity Management in Product/Process Simultaneous Design for Implementing a Fresnel Thermodynamic Solar Plant
}

\author{
Roozbeh Babaeizadeh Malmiry, Nicolas Perry \\ I2M - UMR 5295 - Arts et Métiers ParisTech, F-33400 Talence, France \\ \{roozbeh.babaeizadeh-malmiry, nicolas.perry\}@ensam.eu
}

\begin{abstract}
Fresnel mirror in thermodynamic solar power plant technology is an efficient power resource in many potential countries. The key challenge is cost effectiveness of the product and its settling. The importance of using this technology redounded in writing this paper to propose a methodology in order to design this system considering its complexities. Because of the dependency of the product with process of production and installation of this solar plant, a simultaneous design methodology is required. Moreover, a concept of movable factory, from one solar farm site to another one, is also discussed which is identified as a proper solution for such project with reusability.
\end{abstract}

Keywords: product-process interaction, design methodology, mobile factory design, complexity management, solar power plant, Fresnel

\section{Introduction}

As Tsao stated, "In any given hour, more energy from the sun reaches earth than is used by the entire human population in a given year" [1]. In addition to this fact, solar power, with free and available source of energy in many countries, has the minimum environmental damages among different types of renewable energies [2]. Considering these advantages, although, recently there was a fast growth in solar generation but still according to US Energy information administration; only $13 \%$ of energy is supplied from renewable energies which less than $1 \%$ of that is from solar energy [3], [4]. Therefore, solar energy and specifically the technology of Fresnel mirror has chosen as target market for this paper.

Fresnel Thermodynamic Solar (FTS) technology is a new generation of concentrated solar plants to use the thermal energy of the sun. A FTS system uses the heat of sunray as solar energy and reflects and concentrates this energy by a Fresnel mirrors over a flow of fluid to create steam. This paper focuses on this technology of concentrated solar power plant but the method and discussions can be applied to any other type of project with similar nature.

The target project is to produce and install a 500,000 $\mathrm{m}^{2}$ solar farm (i.e. 50,000 reflectors of $10 \mathrm{~m}^{2}$ and 136 receptors of $240 \mathrm{~m}$ long each) in 6 months. This plant is sup- 
posed to supply energy for at least 40 years [5]. Logistics aspects suggest a movable factory as a relevant solution instead of manufacturing in one place and shipping all the material. In addition, the temporary factory needs to be movable to produce for at least in five different locations.

One of the main issues is the interaction of product with production. Therefore, in the product development aspects, the ease of production and installation method in the process of product design needs to be considered. So, it would be a concurrent designing. To sum up, lack of a systematic methodology for this concurrent designing, together with time limit and the concept of movable factory, makes the design process relatively complex.

Thus, the hypothesis of this paper is to introduce a methodology to design a product and process for planting a FTS system taking into account the complexity of the design process.

\section{Complexity and Variability Management in Design}

According to Seth Lloyd, there are several ways to use the word "complexity" [6]. It can be the amount of computation, scale of measure, or amount of effort which is needed to manufacture a product [7]. The design method of this solar plant is considered as a complex system because;

1. The scale of project considering the required effort is relatively large,

2. The target time limit compared with the size of the project is short,

3. The concept of movable factory is needed to be applied,

4. The product and process is closely dependent on each other.

So, with a methodological design, by means of movable factory, a large part of this complexity would be solved. In addition, different levels of variability as presented by ElMaraghy, have to be faced in this project which leads to a high level of complexity that should be managed [8]. Al-Hakima promotes graph representation to map this complexity [9]. At the information level, the interactions and the exchanged knowledge also have to be mapped [10].

First, the product is designed in a parameterized way (1st level of complexity). Indeed this design has to be adapted to the process of production and installation. Taking into account this potential product variability, the mobile factory has to be designed and optimized, (2nd level of complexity). Moreover, the manufacturing system has its geographical dependencies in terms of logistic aspects, power and water supply as well as potential local supply (3rd level of complexity). All these design solutions should minimize the cost of solar field considering the concentration factor and on the other side the cost of mobile factory should have return on investment after five times solar plant installation [11].

Dealing with solar field design requires defining the objective. This objective mainly could be to have maximum energy from a field, to have minimum field area to achieve a desired amount of energy, or to maximize the energy obtained from collector unit area of a field [12]. 
There are other related complexities in the process as well. For instance the difficulty of protect the installation process from environmental effects because of large project area and environment condition of locations such as deserts.

\section{Methodology}

In the past, many designs have been made empirically, iteratively and intuitively, based on years of experience and creativity with involvement of much trial and error. Therefore, the methodological design has been created to establish a theoretical foundation for engineers in order to increase the creativity and reduce the iterative trialand-error processes [7].

The design process in this project starts from early stage of product/ process definitions. Thus, a good orientation could be a top-down approach from macro model of extracting energy from sun to micro model of components and characteristics. This model is shown in figure 1.

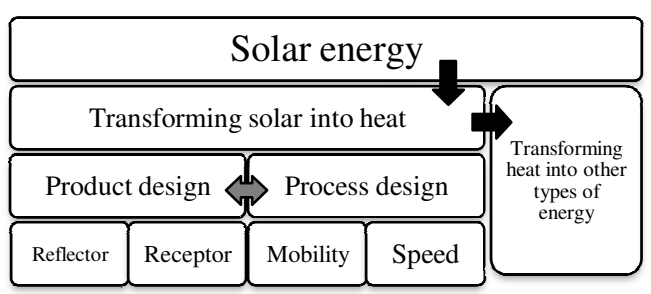

Fig. 1. Top-down approach for design of FTS [5]

As Nam Suh stated in the book of "Axiomatic design", design is the process of mapping between "what we want to achieve" and "how we want to achieve" [7]. In one interpretation, this definition can be interpreted as mapping between product/implantation itself and the process of designing the product/implantation. But, this definition can be adapted to our goal which is the design of product, and design of the process of achieving the product. Since the process must be based on the product and on the other side, in the process of designing the product, the production and installation method also must be considered. Product/Process and Behavioral modeling approaches give possible representation of these interactions [13], [14].

According to axiomatic design, first the aim of the project should be identified and then the functional domain which includes the functional requirements. These functional requirements map the physical domain which includes design parameters and finally the process domain (see figure 2) [15].

The process needs to be divided into sections to be evaluated. For each section, in the process domain, after literature review and examining the basic available methods based on the stages of the process, there are three simple steps; first, choosing the best related methods among the traditional methods; second, combining the traditional methods to create a new method; and third, the innovative ideas which are obtained by brainstorming and taking ideas from similar methods.

This approach has led to create some possible conceptual solutions with keeping an eye on the limitations of the project. These limitations are time, budget, resource availability, and required specifications for the product with high quality and longterm reliability. Then the best method according to the criteria should be chosen. 


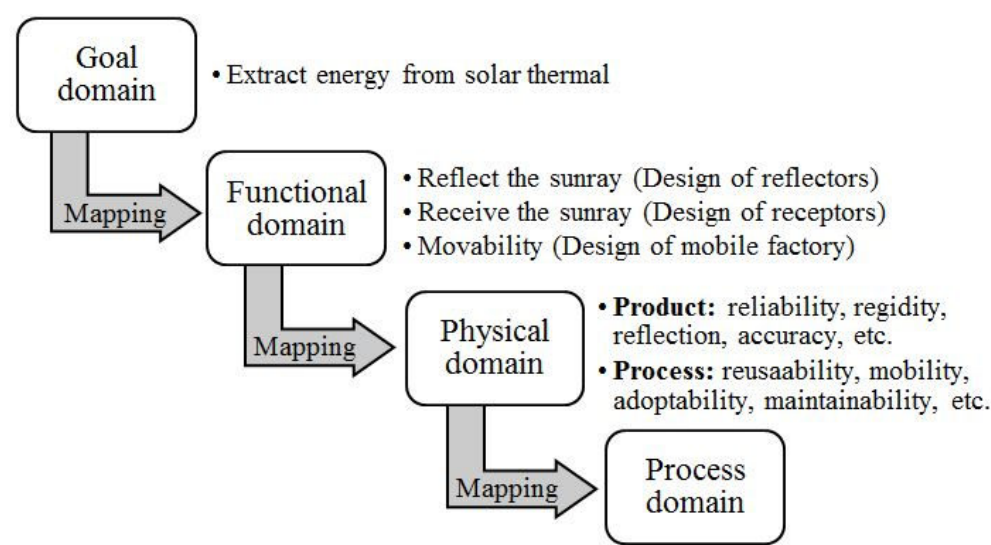

Fig. 3. Four domains for design of FTS

In every stage of design, all the effective factors need to be considered. Figure 3 shows the main factors for a thermodynamic solar plant as IDEF0 (The complete IDEF3 diagram for this project is available in [5]). As it is illustrated in this chart, in the design process, all the material flow, processes, controls and resources should be taken into account. The economical solution will depend on the manufacturing processes and mainly on organizational issues such as material purchase, implementation time, energy and fluid access for the factory.

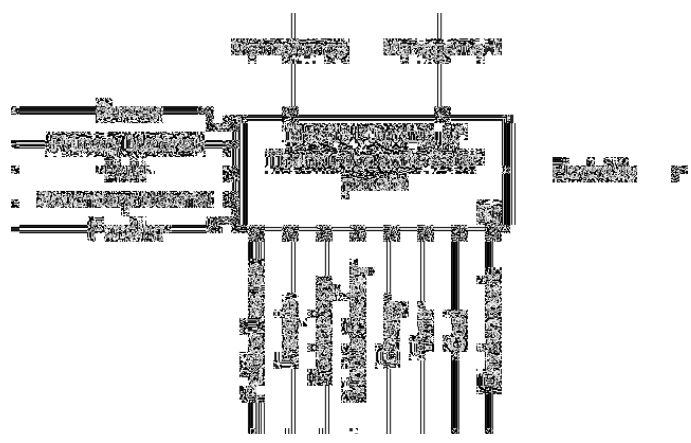

Fig. 4. Key parameters for FTS system analysis [5]

\subsection{Product Design}

In brief, the product in this project consists of two main parts, "reflectors" and "receptors". These two parts are supposed to be installed and work together. So, the process of designing depends on each other. According to the proposed process in Figure 2, first, the characteristics of the product need to be examined. Since the product doesn't exist to be examined, the aim of the product is scrutinized. For instance, the reflectors are expected to reflect the sunray in the most efficient way to the receptors. Moreover, it needs to be rotatable to follow the sunray during the day. Based on these primary objectives, one can characterise the product and shall proceed to the next steps for designing the rotators, connectors, mirrors and the main challenge which is the support. After, these characteristics become more in detail such as size and geometry, structure of support and so on to satisfy the required accuracy and rigidity.

For designing the receptor, with the same procedure, the objective is to receive the concentrated sunray. To obtain this goal, the receptor must contain pipes for the flux 
and also should have an insulator to prevent heat release. This system must implement in the height. Therefore, the receptor must contain several tubes with special material to resist from heat while it conducts the heat to the flux. These pipes need to be hanged using holders. Moreover, the cover of receptor, needs to have flexibility to keep straighten in case of thermal expansion which might be different in top and the bottom side. Also, this cover must carry the insulator too.

\subsection{Process Design}

Beside the product characteristics, the method of production and installation of the plant also needs to be specified. This method is considered as "process" in this paper. As process, managing resources such as material, machines, labor as well as facilities and working conditions are also included. Since our product has two parts of reflector and receptor, one production process has to be designed for each product. Because of dependency of production method with product, the number of process to design would be the combination of these two. It means that, if there are $\mathrm{x}$ number of solutions for designing of reflectors and y number of solutions for designing of receptors, there needs to be $\mathrm{z}$ number of solutions for processes which $z \geq x \times y$ considering $\mathrm{x}$ and $\mathrm{y}$ are dependent. In spite of manufacturing, we also have to design a method(s) to install these elements. Note that, because of the interaction of these two parts, the installation of them must be adopted to each other and also to the criteria. The main criteria for process are: i) ability to produce the whole solar farm elements within 6 months, ii) reusability for at least 5 times, iii) install and uninstall of the factory in two months, iv) ability to move, v) adoptability with different locations.

So, factors such as time, reusability, reliability, adoptability and mobility need to be considered during the process of design (figure 2). In this case also the similar methodology of design should be followed. Different stages of the production and assembly line as well as installation stage need to be examined. In most of the production and installation stages, the process is known and could be applied. By considering the criteria, the most suitable method should be chosen and any method needs to be adjusted along with the goal domain.

The production environment has an important role in this project. For instance access to energy, working temperature, dust and etc. will affect the plant and working facilities design. The installation equipment should be portable to cover large area. Levels of portability which will be discussed in next section also need to be chosen. In several design solutions, dividing the processes of production and installation is not appropriate. Modular design of the factory can be applied using shipping containers as structure module.

\section{Product/Process Evaluation Tool}

As it is mentioned earlier, one of the most complex issues in this project is the interaction of design factors in this project. Interaction between the different levels and product-process is mapped using graph representation as illustrated in figure 4 . 


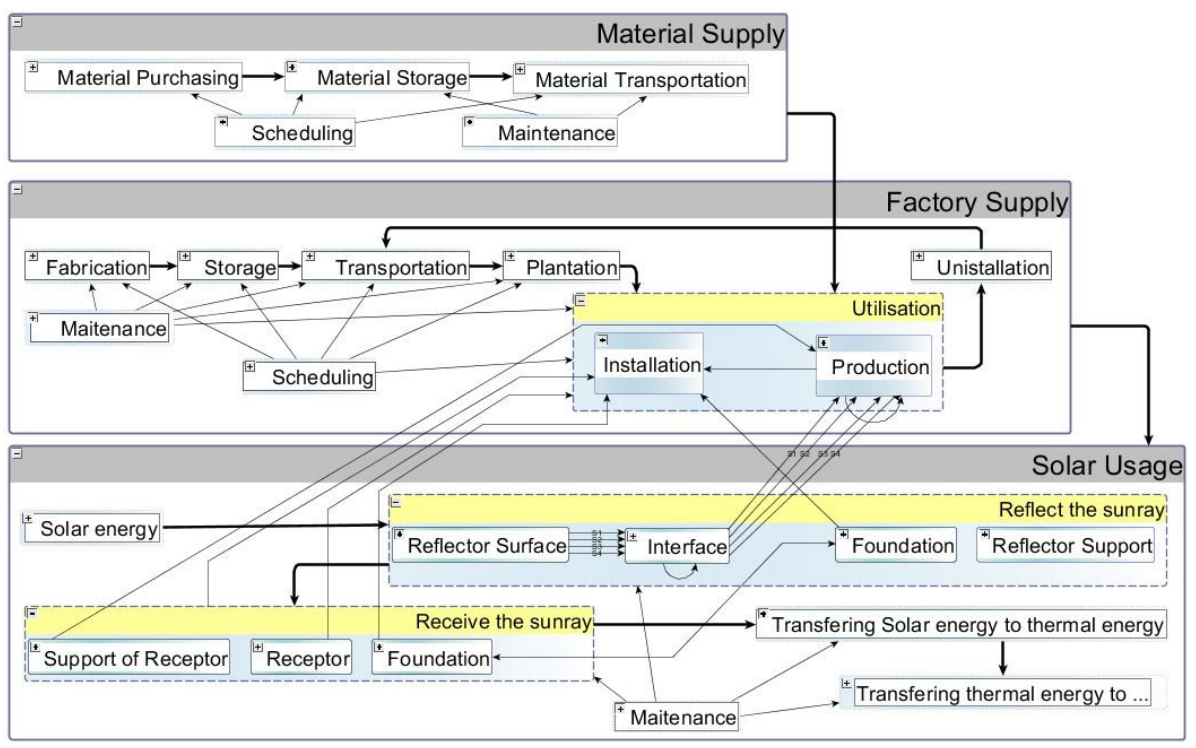

Fig. 5. Product/process elements interactions [5]

After designing stage, regarding these links, each design solution need to be evaluated based on: 1) Process steps and sub-steps, 2) Cycle times, 3) Throughput time, 4) Human resource (number and skills), 5) Types and cost of material, 6) Type and cost of machines, 7) Number of container needed to move the factory, 8) Number of container needed to supply the materials, 9) Bottle necks, 10) Machines' efficiency, 11) Product mass and weight, as presented in Appendix A.

For cost evaluation, reusability of the mobile factory needs to be considered. Assuming five times for reusability, the total cost will be calculated as;

Total cost of $\mathbf{1}$ solar plant $=$

$[\mathbf{5} \times$ Cost of material $+\mathbf{5} \times$ Cost of (Transportation, Labor ... $)+\mathbf{1} \times$ Cost of factory $] / \mathbf{5}$

\section{$5 \quad$ Movable Factory Design}

As an initial idea for this project, the project supposed to be implemented in North Africa but the special resources are available in source country which is considered as France. By special resource, it is meant materials and machines which are not found in many places (especially North Africa) as well as experts, robots and customized equipment. In addition, the process supposed to be used for more than one project. In this case, the first idea could be to build the product in origin and transport to the destination.

As table 1 illustrates, the cost of transportation for only reflectors panel will be about $775 \mathrm{k} €$ which makes the project non economical. While, if the material is transported instead of ready panels, the cost would be around $32 \mathrm{k} €$ which is significantly cheaper. This difference, even without considering the reduction in possible damages 
during the transportation can justify transporting labor, equipment and etc. and producing in the destination point in case of receptors, the $200 \mathrm{~m}$ length requirement, rationalizes the proposed transportation method even more. Hence, the concept of mobile factory is used in this project.

Table 1. cost of transportation for ready panels vs. materials from France to North Africa

\begin{tabular}{|c|c|c|c|}
\hline 40ft Container & \multicolumn{3}{|c|}{$\begin{array}{l}\text { Size: } 12 \mathrm{~m} \times 2.35 \mathrm{~m} \times 2.4 \mathrm{~m} \text {, Volume limit: } 37 \mathrm{~m}^{3} \text {, Weight limit: } 36500 \mathrm{~kg} \\
\text { transportation cost of each container: } 340 € \\
\text { Fixed transportation cost: } 2,300 €\end{array}$} \\
\hline & & Required container & Estimated cost of transportation \\
\hline \multicolumn{2}{|l|}{ Prepared panels } & 2273 & $775 \mathrm{k€}$ \\
\hline \multicolumn{2}{|c|}{ Materials (Glass \& Aluminum) } & 88 & $32 \mathrm{k€}$ \\
\hline
\end{tabular}

As DesJardin presents, there are three major level of mobility for a factory; Fixed, transportable and portable. Various factors should be considered to make a factory in high level of portability such as size reduction, weight reduction and power source [16]. In this project, there are two aspects of mobility. First, because of the size and complexity of the product, it's not possible to move the finished goods. So, the idea is to move the material, equipment, labor, and energy source to the destination and then produce and install at site.

The concept of movable factory is not limited to solar plant. Offshore workshop, used in Navy, is a good example of movable production system which enables carrying the missions' maintenance system anywhere in the world. Movable assembly line is another example of using this concept in aerospace industry to have a leaner and more efficient production system.

Second aspect is to use portable factory. A portable factory which is also dubbed as "factory in a box" is a pre-assembled group of equipment which is transportable and can be used as plug-and-play in site. These kinds of buildings are just placed in the site and can be easily removed and transported to another place afterwards. In such buildings, features such as HVAC system, energy generators, etc. could be housed in a $20 \mathrm{ft}$ shipping container which can be shipped, trucked or airlifted to any location.

Thus, in the process of production and installation design for such project, movable factory based on the level of mobility, factory life cycle, interdependency of process and product, and other issues needs to be designed.

Before starting to design, the life cycle of the process to build the solar plant needs to be examined. This cycle includes preparation, storage, transportation, installation, use, and uninstallation. The transportation stage means either to move from the source to the project site or from one project to another. In this stage, three categories of human resource, machines and robots, and material need to be transported. In each category some elements could be used by local resources while others need to be transported. Table 2 is the summery of these elements and the way to utilize. The cycle starts from the preparation of equipment, materials, labors, etc.

The installation stage means to install the temporary factory (e.g. in 6 months) in order to build the solar plant and in "use" stage the factory is used to produce the components and install it. 
Table 2. Using local resources vs. transporting resources

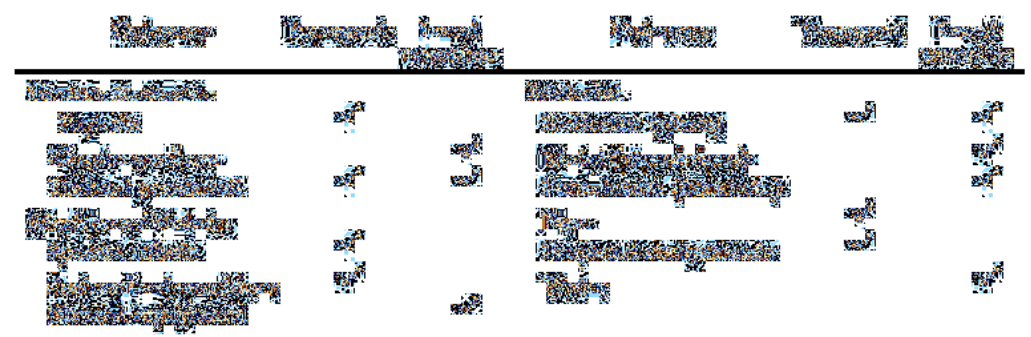

Because of the difficulty of components like receptor, and time shortage, these two stages need to be done in parallel with a proper scheduling. For fast establishment of large area foundation, machines such as concert slip forming machine, asphalt finisher, track renewal train and etc. could be occupied. These machines create a flat surface which makes it easy for equipment and labor to move in the project area especially for portable factories and also it can be used to install the solar plant components. After installation and use, with considering the concept of green factory, all the equipment of plant production must be collected from the site except those which are necessary for the utilizing the solar plant.

\section{Conclusion and Discussions}

This paper proposed an example and the starting elements of a methodology in order to deal with complexity in design of product and production/installation process with bearing in mind the cost, quality and time. The main complexity which is faced first in this project is the interaction of product with process which made it necessary for a concurrent designing. The next level that must be integrated is the adaptability and reliability requirements due to mobility.

To evaluate a design as a "good design", at first the goal has to be identified. So, this methodology is started from goal domain. This goal maps the functional requirement which maps the physical domain for product and process. Finally, in the process domain, the procedure needs to be divided properly and the three steps apply for each section.

After designing the product and processes, the solution needs to be evaluated by the "evaluation tool" which was proposed. By means of this tool, different solutions of product design would be examined and subsequently, the design of process is evaluated. Regarding the goal domain, the design decision is made based on the result which includes cost, scheduling, number of containers, etc.

After the conceptual design phases, other aspects such as movable factory are also integrated which according to the project, the level of movability needs to be chosen. This movability makes the process less expensive in transportation, more efficient for covering large area, and possible to be reused for at least five times. The reason of choosing "five" as reusability is that considering transportation time, inventory waiting time and production time, five times of implanting a solar power plant takes about 
5 to 7 years. After this time most probably the product is no longer on top of technology and should be replaced by a competing product which gives a better performance.

Since the time is so limited in this project in comparison with size of the project, milestones are substantial to be scheduled and therefore each process needs to be illustrated as simogram. This Gaunt chart is fundamental as far as so many processes may happen in parallel in this project and it's crucial to have them all on time.

This methodology, using the evaluation tool, works as a dynamic tool for "what-if" scenario. At any stage, one factor can be modified and the result is being observed. However, the discussion is for the early stage of design and the next developments will give more precise rules for evaluation (costs or time). These sharper equations can be easily integrated in the evaluation tool and use its final results (input/output data). After evaluation of the solutions, if the result is not satisfactory, the characteristics of domains change and then the method applies again until the desired result is achieved.

\section{References}

1. Tsao, J., Lewis, N., Crabtree, G.: Solar FAQs, US department of Energy (2006)

2. Jayakumar, P.: Resource Assessment Handbook, APCTT (2009)

3. US National Academy of Engineering: A Grand Challenge for the Twenty-first Century: Commercializing Solar Energy, Strategic Direction, vol. 24 Iss: 7 pp. 33-36 (2008)

4. Quoilin S.: Concentrating Solar Power Plants, Université de Liège (2007)

5. Babaeizadeh Malmiry, R.: Product-Process Interaction Analysis: Design of Mobile Factory for Fresnel Thermodynamic Solar Plant, Master Thesis, Arts et Metiers - ParisTech (2012)

6. Lloyd, S., Pagels, H.: Complexity as Thermodynamic Depth, Annals of Physics, vol. 188, pp. 186-213 (1998)

7. Suh, N.P.: Axiomatic Design: advances and applications, Oxford University Press, New York (1986)

8. ElMaraghy, W., ElMaraghy, H., Tomiyama, T., Monostori, L.: Complexity in Engineering Design and Manufacturing, vol. 61/2 (2012)

9. Al-Hakima, L., Kusiak, A., Mathew, J.: A Graph-theoretic Approach to Conceptual Design with Functional Perspectives, Computer-Aided Design, Vols. 32-14, pp. 867-875 (2000)

10. Bernard A., Labrousse M., Perry N.: LC Universal Model for the Enterprise Information System Structure: Innovation in Life Cycle Engineering and Sustainable Development, Springer, pp. 429-448 (2005)

11. SYNDICAT, Directory of the French Solar Thermodynamic Industry (2011)

12. Weinstock, D., Appelbaum, J.: Optimal solar field design of stationary collectors, Journal of solar energy engineering, pp. 898-905 (2004)

13. Qian L., Gero J.S.: Function-Behavior-Structure Paths and Their Role in Analogy-Based Design, AIEDAM, pp. 289-312 (1996)

14. Umeda Y.: Functional Reasoning in Design, IEEE Expert, pp. $42-48$ (1997)

15. Labrousse M., Bernard A., Véron P.: Generic FBS concept for Process/Product/Resource integration, in Tools and Methods of Competitive Engineering, Vol 1, pp.384-394

16. DesJardin, L.: DOWNSIZING WITH VXIbus: Opportunities and Limitations in Factory, Field, and Portable environments, IEEE, pp. 55-62 (1989) 


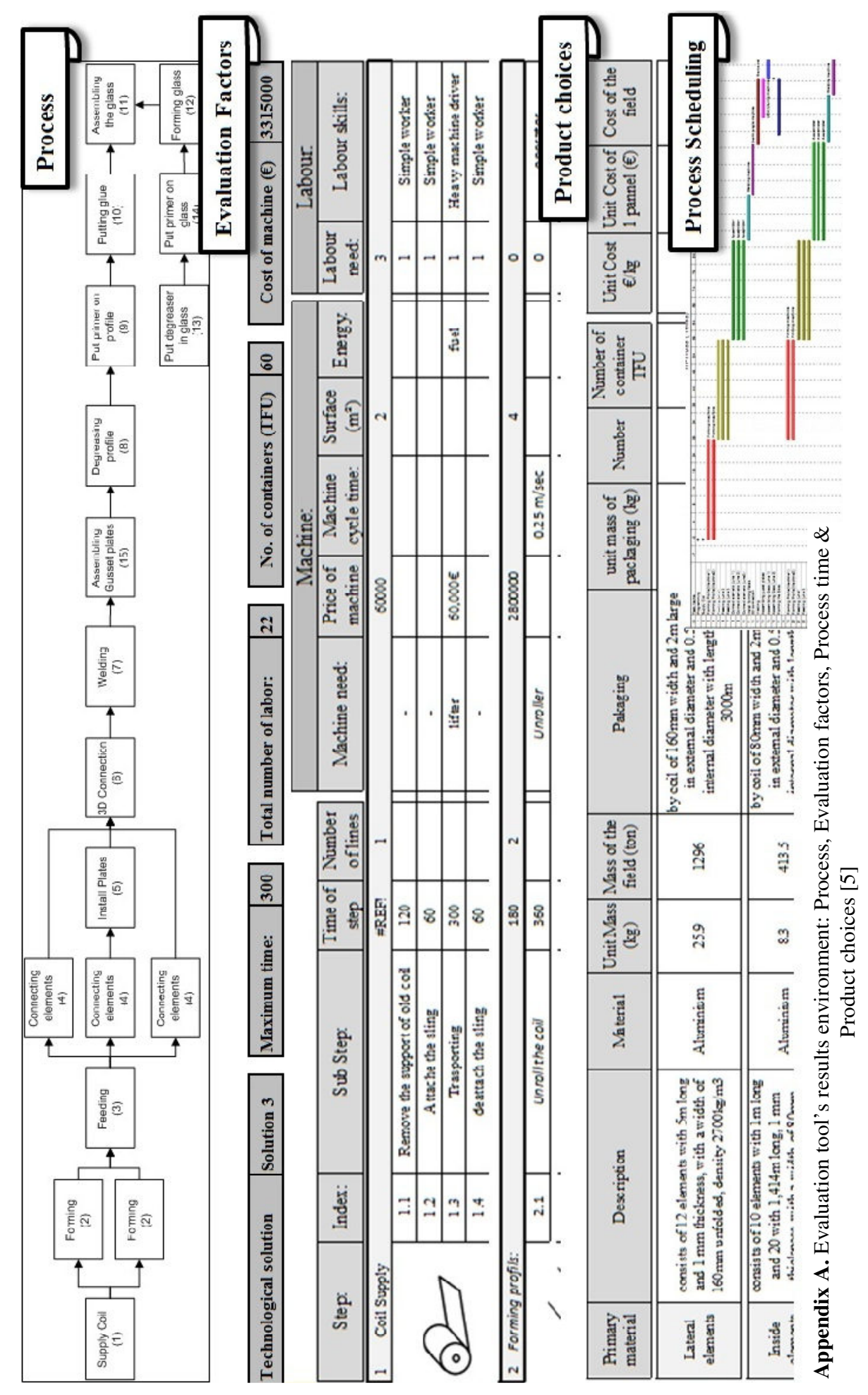

